\title{
A Novel Organ Culture Model of Mouse Intervertebral Disc Tissues
}

\author{
Zhengjian Yan ${ }^{a, h}$ Liangjun Yin ${ }^{a, h}$ Zhongliang Wang ${ }^{b, h}$ Jixing $\mathrm{Ye}^{\mathrm{c}, \mathrm{h}}$ \\ Zhonglin Zhang ${ }^{\mathrm{d}, \mathrm{h}}$ Ruifang $\mathrm{Li}^{\mathrm{d}, \mathrm{h}}$ Sahitya K. Denduluri ${ }^{\mathrm{h}}$ Jing Wang ${ }^{\mathrm{b}, \mathrm{h}}$ \\ Qiang Wei ${ }^{b, h}$ Lianggong Zhao ${ }^{e, h}$ Shun Lu ${ }^{f, h}$ Xin Wang ${ }^{g, h}$ Shengli Tang ${ }^{d, h}$ \\ Lewis L. Shi ${ }^{\text {h }}$ Michael J. Lee ${ }^{h}$ Tong-Chuan He ${ }^{b, h}$ Zhong-Liang Deng ${ }^{a}$ \\ ${ }^{a}$ Department of Orthopaedic Surgery, The Second Affiliated Hospital, Chongqing Medical University, ${ }^{b}$ Ministry of \\ Education Key Laboratory of Diagnostic Medicine and the Affiliated Hospitals of Chongqing Medical University, and \\ 'School of Bioengineering, Chongqing University, Chongqing, d Departments of Neurology and Surgery, \\ The Affiliated Hospitals of Wuhan University, Wuhan, e Department of Orthopaedic Surgery, The Second Affiliated \\ Hospital of Lanzhou University, Lanzhou, ${ }^{f}$ Department of Orthopaedic Surgery, The Affiliated Shandong Provincial \\ Hospital of Shandong University School of Medicine, Jinan, and ${ }^{9}$ Department of Surgery, The Affiliated West China \\ Hospital of Sichuan University, Chengdu, PR China; ${ }^{h}$ Molecular Oncology Laboratory, Department of Orthopaedic \\ Surgery and Rehabilitation Medicine, The University of Chicago Medical Center, Chicago, III., USA
}

\section{Key Words}

Intervertebral disc - Nucleus pulposus - Annulus fibrosus . Organ culture $\cdot$ Recombinant adenovirus $\cdot$ Tissue engineering $\cdot$ Gene delivery

\begin{abstract}
The intervertebral disc (IVD) is a fibrocartilaginous joint between two vertebral bodies. An IVD unit consists of a gelatinous central nucleus pulposus, encased by the annulus fibrosus, which is sandwiched between cartilaginous endplates (EPs). The IVD homeostasis can be disrupted by injuries, ageing and/or genetic predispositions, leading to degenerative disc disorders and subsequent lower back pain. The complex structure and distinct characteristics of IVDs warrant the establishment of robust in vitro IVD organ culture for studying the etiology and treatment of disc degeneration. Here, we isolate mouse lumbar IVDs and culture
\end{abstract}

\section{KARGER} www.karger.com/cto
E-Mail karger@karger.com the minimal IVD units in submersion or suspension medium supplemented with $2 \%$ bovine serum or $10 \%$ fetal bovine serum (FBS). We find the minimal IVD units remain healthy for up to 14 days when cultured in submersion culture supplemented with $10 \%$ FBS. New bone formation in the EPs of the cultured IVDs can be assessed with calcein labeling. Furthermore, the cultured IVDs can be effectively transduced by recombinant adenovirus, and transgene expression lasts for 2 weeks. Thus, our findings demonstrate that the optimized IVD organ culture system can be used to study IVD biology and screen for biological factors that may prevent, alleviate and/or treat disc degeneration.

(c) 2015 S. Karger AG, Basel
T.-C. $\mathrm{He}, \mathrm{MD}, \mathrm{PhD}$

Molecular Oncology Laboratory, Department of Orthopaedic Surgery and

Rehabilitation Medicine, The University of Chicago Medical Center

5841 South Maryland Avenue, MC 3079, Chicago, IL 60637 (USA)

E-Mail tche@bsd.uchicago.edu

Zhongliang Deng, $\mathrm{MD}, \mathrm{PhD}$

Department of Orthopaedic Surgery

The Second Affiliated Hospital, Chongqing Medical University

Chongqing 400010 (PR China)

E-Mail zhongliang.deng@qq.com 


\begin{tabular}{ll}
\hline Abbreviations used in this paper \\
\hline AF & annulus fibrosus \\
BS & bovine serum \\
DMEM & Dulbecco's modified Eagle's serum \\
EPs & endplates \\
FBS & fetal bovine serum \\
HE & hematoxylin and eosin \\
IVD & intervertebral disc \\
NP & nucleus pulposus \\
PCNA & proliferating cell nuclear antigen \\
\hline
\end{tabular}

\section{Introduction}

The intervertebral discs (IVDs) along the spine provide motion and protection against mechanical loading [Pattappa et al., 2012]. The IVD is a functional unit connecting the vertebral bodies of the spine and is a complex fibrocartilaginous structure consisting of a gelatinous central nucleus pulposus (NP), encased by the annulus fibrosus (AF), which is sandwiched between rostrally and caudally positioned cartilaginous endplates (EPs) [Roughley, 2004; Raj, 2008; Chan et al., 2011; Pattappa et al., 2012; Sivakamasundari and Lufkin, 2012; Kepler et al., 2013]. Each of these components has a specific function and consists of a specific matrix structure that is maintained by a cell population with a distinct phenotype [Pattappa et al., 2012]. It has been well established that the notochord is central to the development of IVD. The notochord is a rod-shaped midline structure of mesodermal origin found in chordate embryos during gastrulation, and represents a primitive axial skeleton. Thus, the notochord is essential not only as a signaling center, but also as a structure that gives rise to the future NP [Chan et al., 2011; Sivakamasundari and Lufkin, 2012]. The AF and cartilage EPs are sclerotome-derived structures. The AF consists of concentric inner and outer regions with a distinct biochemical cellular composition and biomechanical properties. The outer AF is composed of fibroblastic cells, which produce type I collagen, while cells in the inner AF are more chondrocyte-like, producing mainly type II collagen and proteoglycans [Chan et al., 2011]. EPs are composed of an inner bony layer and an outer cartilaginous layer. The latter is a thin horizontal layer of articular cartilaginous structure, which interfaces the vertebral bodies and the IVDs [Chan et al., 2011; Dahia et al., 2011]. The IVDs have a limited nerve and blood vessel supply, and the EPs function as the source and regulator of nutrient and oxygen diffusion from the vertebral bod-

Adenovirus-Mediated Gene Transfer into

Mouse IVD Explants ies [Raj, 2008; Chan et al., 2011; Dahia et al., 2011]. Thus, the IVDs are a highly organized and delicate structure [Roughley, 2004; Raj, 2008].

Healthy IVDs are able to maintain disc homeostasis through a balanced slow matrix turnover of synthesis and degradation, which is often disturbed by injuries, ageing and/or genetic predispositions, leading to degenerative disc disorders [Chan et al., 2011]. Lower back pain is a leading debilitating condition that affects every population worldwide [Andersson, 1999]. Although lower back pain is considered a multifactorial condition, IVD degeneration is a strong etiologic factor [Andersson, 1999; Chan et al., 2011; Eskola et al., 2012; Kepler et al., 2013]. A biochemical hallmark of degenerative disc disease is decreased proteoglycan content of the IVD, which reduces the water retention ability of the NP and leads to a marked increase in the amount of collagen [Sivakamasundari and Lufkin, 2012; Kepler et al., 2013]. We previously showed that exogenous expression of Sox9 in IVD cells may slow down disc degeneration [Paul et al., 2003; Jo et al., 2014]. Nonetheless, the molecular events underlying the pathogenic process of disc degeneration remain to be fully understood [Kepler et al., 2013]. Understanding the cellular and molecular characteristics of the functional IVD is key to successful therapeutic management of IVD degeneration. Thus, effective in vitro and ex vivo manipulations of the IVD cells should be of significant interest from several perspectives, such as development, growth, remodeling, degeneration and repair.

In this study, we develop and characterize an in vitro IVD organ culture system. Specifically, we isolate mouse lumbar IVD tissues and culture the organ explants in submersion or suspension medium, supplemented with either $2 \%$ bovine serum (BS) or $10 \%$ fetal BS (FBS). We find that disc cells in the minimal IVD units remain healthy and can survive for up to 14 days, based on histologic evaluation and proliferating cell nuclear antigen (PCNA) expression detection, when cultured in submersion culture supplemented with $10 \%$ FBS. Furthermore, the new bone formation and mineralization of the EPs in the cultured IVD organ explants can be dynamically assessed by labeling with the fluorescent dye calcein. The cultured IVD organ explants can be effectively transduced by recombinant adenovirus, and transgene expression lasts at least 2 weeks. Taken together, our findings demonstrate that the reported IVD organ culture system can be used to study IVD cell biology and screen for biological factors that may prevent, alleviate and/or treat disc degeneration disease. Ultimately, any success- 
ful cell-based and tissue engineering approaches to regenerative therapies require a clear understanding of the characteristics of individual IVD tissues in the context of whole organ functions.

\section{Materials and Methods}

\section{Cell Culture Medium and Chemicals}

HEK-293 cells were purchased from ATCC (Manassas, Va., USA) and 293pTP cells were engineered as previously reported by Wu et al. [2014]. Both cell lines were maintained in complete Dulbecco's modified Eagle's medium (DMEM; with 4.5 g/l glucose) supplemented with 10\% FBS (Invitrogen, Carlsbad, Calif., USA), 100 units $/ \mathrm{ml}$ penicillin and $100 \mu \mathrm{g} / \mathrm{ml}$ streptomycin at $37^{\circ} \mathrm{C}$ in $5 \%$ $\mathrm{CO}_{2}$ as described previously [Zhang et al., 2013; Deng et al., 2014; Wang et al., 2014a-c; Wen et al., 2014; Chen et al., 2015; Zhang et al., 2015]. All chemicals were purchased from Fisher Scientific (Pittsburgh, Pa., USA) or Sigma-Aldrich (St. Louis, Mo., USA) unless otherwise noted.

\section{Isolation and Dissection of Lumbar IVD Tissues}

All animal-related experiments in this study followed the animal use and care guidelines approved by the institutional animal care and use committee. Two-week-old male CD1 mice were obtained from The University of Chicago Transgenic Animal Core Facility. The mice were euthanized, and the lumbar spine segments were dissected out under sterile conditions using the Olympus SZX16 micro-dissection stereomicroscope (fig. 1A). The dissected IVDs were briefly rinsed in sterile PBS and immediately placed in culture medium-containing 24-well cell culture plates (fig. 1B).

\section{Preparation of IVD Culture Medium}

Two types of DMEM (with $4.5 \mathrm{~g} / \mathrm{l}$ glucose) culture medium were used in the study: (1) 2\% BS - DMEM containing 2\% BS (Hyclone, Logan, Utah, USA) and $100 \mathrm{units} / \mathrm{ml}$ penicillin, and $100 \mu \mathrm{g} /$ $\mathrm{ml}$ streptomycin; (2) 10\% FBS - DMEM containing 10\% FBS and $100 \mathrm{units} / \mathrm{ml}$ penicillin, and $100 \mu \mathrm{g} / \mathrm{ml}$ streptomycin.

\section{The Set-Up of the Two IVD Culture Systems}

Two systems were used to culture the dissected IVD tissue samples. The first was submersion culture in which the IVD tissue samples were completely submersed into the individual wells of 24 -well cell culture plates filled with either $10 \%$ FBS or $2 \%$ BS (fig. 1C, panel a). The second was suspension culture (fig. 1C, panel b) in which a sterile 8 -mm-diameter spin column (without a filter membrane) was first placed at the center of each well of 24well plates, which were filled with $10 \%$ FBS or $2 \%$ BS medium. The bottom half of each column was first loosely stuffed with cotton balls semisaturated with medium, and then the IVD tissue sample was placed at the center of the column, which was subsequently filled with further medium-semisaturated cotton balls (fig. 1C, panel c). In both culture systems, the culture medium (approx. 1.0 $\mathrm{ml}$ per well) was changed every $48 \mathrm{~h}$ until the end points of the assays. In most assays, the sample size was usually between 5 and 8 IVD samples per culture condition per time point, as indicated in the figure legends.
Generation and Amplification of the Recombinant Adenovirus AdGFP

Recombinant adenovirus was generated using the AdEasy technology as previously described [Cheng et al., 2003; Kang et al., 2004; Luo et al., 2007; Kang et al., 2009]. The coding region of eGFP was PCR amplified and cloned into an adenoviral shuttle vector, and subsequently used to generate and amplify recombinant adenovirus in HEK-293 or 293pTP cells [Wu et al., 2014]. The resulting adenovirus was designated as AdGFP [Gao et al., 2013; Kong et al., 2013; Liu et al., 2013; Wang et al., 2013]. For all adenoviral infections, Polybrene $(4-8 \mu \mathrm{g} / \mathrm{ml})$ was added to enhance the infection efficiency as previously reported [Zhao et al., 2014].

\section{Immunohistochemical Staining of the Cultured IVD Samples}

The IVDs cultured in 10\% FBS medium in either submersion culture or suspension culture for 14 days were subjected to paraffin embedding and sectioning. The sections were deparaffinized, rehydrated and subjected to immunohistochemical staining with an anti-PCNA antibody (Santa Cruz Biotechnology, Santa Cruz, Calif., USA) and an HRP-conjugated secondary antibody (Jackson ImmunoResearch Laboratories, West Grove, Pa., USA). The positive stain was visualized by DAB development. Staining without primary antibody and with control IgG served as the negative control.

\section{Calcein Staining of the Cultured IVD Samples}

The isolated IVD tissues were incubated in DMEM containing $10 \% \mathrm{FBS}, 50 \mu \mathrm{g} / \mathrm{ml}$ ascorbic acid, $1 \mu \mathrm{M} \beta$-glycerophosphate, 100 $\mathrm{mg} / \mathrm{ml}$ penicillin-streptomycin solution and $100 \mathrm{~mm}$ calcein. At the indicated time points, the cultured IVDs were examined under bright field and/or fluorescence stereomicroscopes. The harvested IVDs were also subjected to frozen sectioning and examined under a fluorescence microscope.

\section{Histologic Evaluation}

The cultured tissues were snap frozen in the OCT medium. Serial sections of the embedded specimens were stained with hematoxylin and eosin (HE).

Fig. 1. Isolation and culture of the mouse IVD tissues. A Two-weekold male CD1 mice were euthanized and the lumbar spine was carefully resected (a); excessive soft tissues were removed (b). B To dissect out individual IVD tissue samples, the isolated lumbar spine segments were further cut to allow each disc sample containing the edges of both EPs (a, dotted yellow boxes), while unnecessary soft tissues were trimmed away (b). C Two approaches for culturing dissected IVD samples were investigated: submersion culture - the trimmed IVD tissue samples were completely submersed in individual wells of 24-well cell culture plates filled with either 10\% FBS/ DMEM or 2\% BS/DMEM (a); suspension culture - a sterile 8-mmdiameter spin column (without a filter membrane) was first placed at the center of each well of 24-well plates, which were filled with $10 \%$ FBS or $2 \%$ BS medium; the bottom half of each column was first loosely stuffed with cotton balls semisaturated with medium, and then the IVD tissue sample was placed at the center of the column, which was subsequently filled with medium-semisaturated cotton balls $(\mathbf{b}, \mathbf{c})$. In both culture systems, culture medium was changed every $48 \mathrm{~h}$ until the end points of the assays.

(For figure see next page.)
Yan et al. 

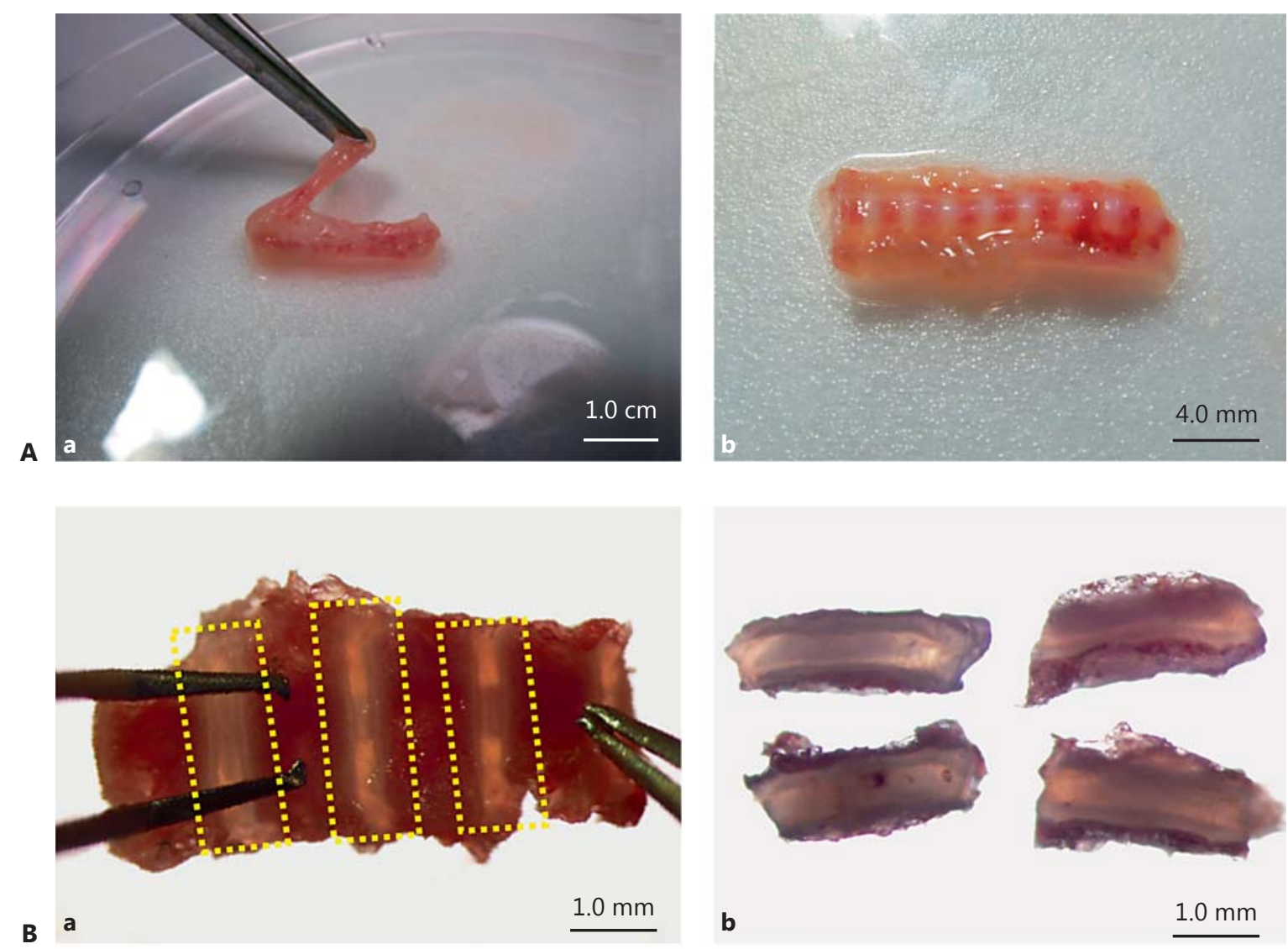

Submersion culture
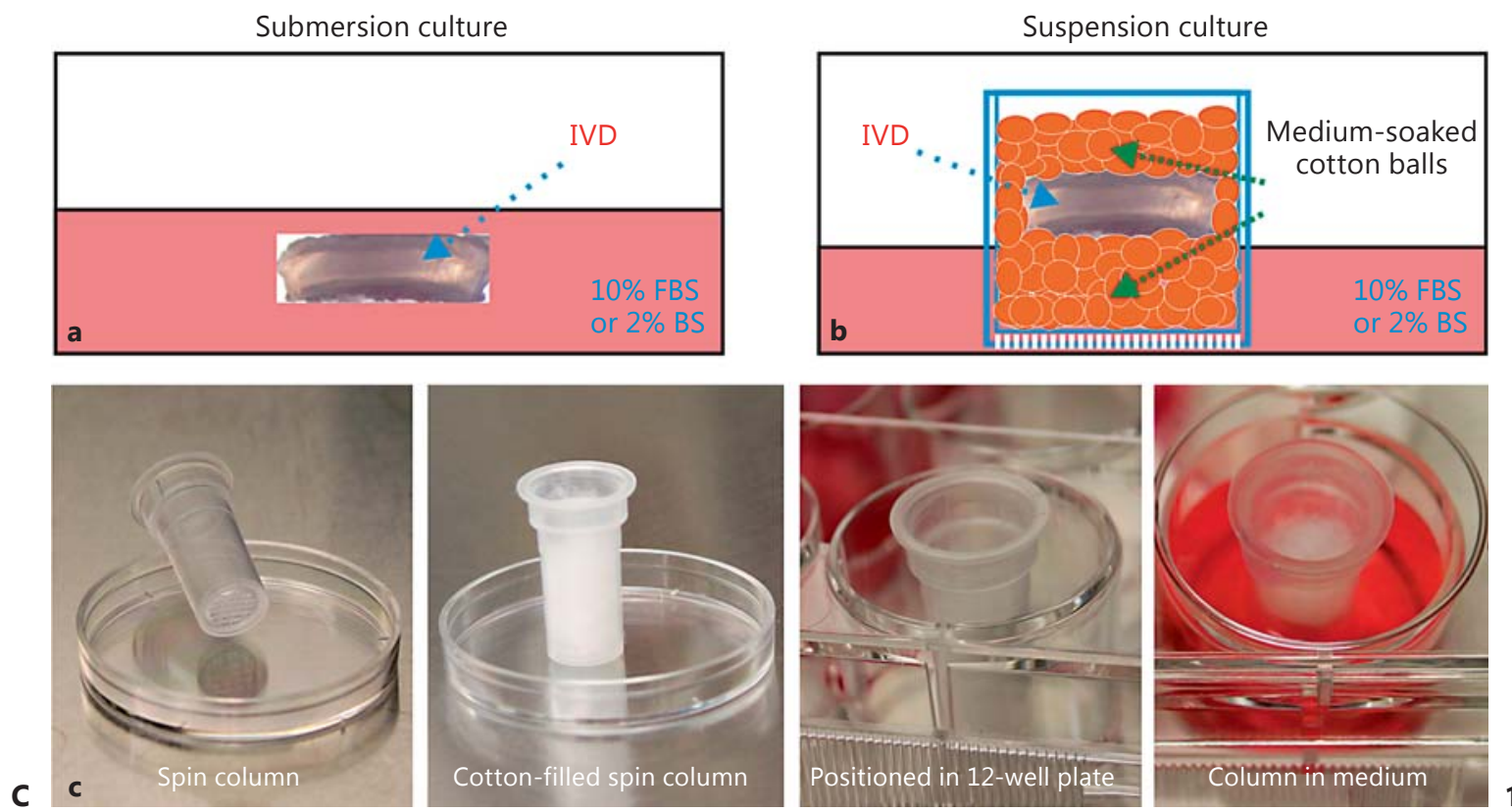


\section{Results and Discussion}

\section{Isolation and Establishment of Mouse IVD Tissues for} in vitro Organ Culture

We first isolated mouse IVD tissues for in vitro organ culture. After euthanizing the 2-week-old male CD1 mice, we carefully dissected out the lumber spine segment under a stereomicroscope (fig. 1A, panel a). In order to get a clear exposure of the discs and their adjacent intervertebral bodies, we further removed excessive soft issues from the IVD segment (fig. 1A, panel b). Under the stereomicroscope, we marked each IVD unit, which contains the fullthickness IVD and the neighboring EPs (approx. 30\% of the adjacent intervertebral bodies; fig. 1B, panel a), and resected each IVD unit as an individual organ culture unit (fig. 1B, panel b). The isolated IVD samples were immediately used for in vitro organ culture.

We next sought to optimize in vitro culture conditions for mouse IVD tissues. While tissue explants and IVD cultures have been previously described [Pelle et al., 2014; Gantenbein et al., 2015; Gorth et al., 2015], our preliminary studies indicated that the cultured disc tissues degraded rather quickly, usually within 5 days. Considering the relatively hypoxic environment for the IVD cells, we designed two culture systems: the submersion culture and suspension culture systems (fig. $1 \mathrm{C}$, panels b, c). In the submersion culture system, the trimmed IVD tissue samples were completely submersed in individual wells of 24well cell culture plates filled with medium (fig. 1C, panel a). For the suspension culture system, a sterile 8 -mm-diameter spin column (without a filter membrane) was first placed at the center of each well of 24-well plates, which were filled with medium. The bottom half of each column was first loosely stuffed with cotton balls semisaturated with medium, and then the IVD tissue sample was placed at the center of the column, which was subsequently filled with further medium-semisaturated cotton balls (fig. 1C, panels $b, c$ ). To change the medium in the suspension system, the medium outside the column was completely removed from each well and fresh medium (about $1.0 \mathrm{ml}$ ) was added directly into the columns.

We also tested the effects of culture medium on the long-term health status of the IVD tissues. We previously used BSA-containing medium for culturing tissue explants [Chen et al., 2010; Zhang et al., 2010; Huang et al., 2012]. Based on our prior work and pilot studies, we chose to test the following two types of culture medium conditions: 10\% FBS/DMEM and 2\% BS/DMEM. In both culture systems, the medium was changed every $48 \mathrm{~h}$ until the end points of the assays (fig. 1C).
The Submersion Culture System Provides Better Survival Conditions for the Cultured IVD Tissues in 2\% BS Medium

We placed the isolated lumbar IVD tissue samples in both the submersion culture and suspension culture systems, and cultured them in 2\% BS/DMEM medium for 3 , 7 and 14 days ( $\mathrm{n}=6$ for each time point). At each end point, the cultured IVD units were harvested and subjected to sectioning and HE staining. In the suspension culture, cells in three anatomical regions, the AF, NP and EP, appeared healthy on day 3 (fig. 2a). On day 7 , the AF and EP cells were relatively healthy, while significant nucleus condensation with karyopyknosis was observed in the NP cells (fig. 2a). On day 14, apparent necrosis or apoptosis was observed in all three types of cell population in the tissue samples (fig. 2a). These results indicate that the suspension culture system may only support short-term survival of the IVD tissues in 2\% BS-supplemented medium.

In the submersion culture system with 2\% BS/DMEM, we found that the AF, NP and EP cells showed survival on day 3 and day 7 (fig. 2b). However, on day 14 the NP and EP cells displayed significant necrosis or apoptosis, though some AF cells still appeared healthy (fig. 2b). These results suggest that using the $2 \%$ BS/DMEM submersion culture system may support IVD cell survival more efficiently than the suspension culture system. However, in either system, the cultured IVD tissues appeared unhealthy within 2 weeks in the $2 \%$ BS/DMEM culture condition.

IVD Tissues Survive Better in the Submersion Culture System with 10\% FBS Medium

We next tested the IVD cells' survival under the $10 \%$ FBS/DMEM culture condition when the isolated lumbar IVD tissue samples were cultured in both the submersion culture and suspension culture systems for 3, 7 and 14 days ( $\mathrm{n}=6$ for each time point). At each end point, the cultured IVD units were harvested and subjected to sectioning and HE staining. In the suspension culture, all three cell types (AF, NP and EP) were apparently healthy

Fig. 2. The growth and health status of IVD tissues cultured in $2 \%$ BS medium. The isolated lumbar IVD tissue samples were maintained in $2 \%$ BS medium either in suspension culture (a) or submersion culture (b; $n=6$ per culture condition per time point). On days 3, 7 and 14, the cultured IVD samples were fixed, decalcified and subjected to paraffin embedding and sectioning. Slides were stained with HE. Representative images of the AF, NP and EP regions of the IVD samples are shown.

(For figure see next page.)
Yan et al. 

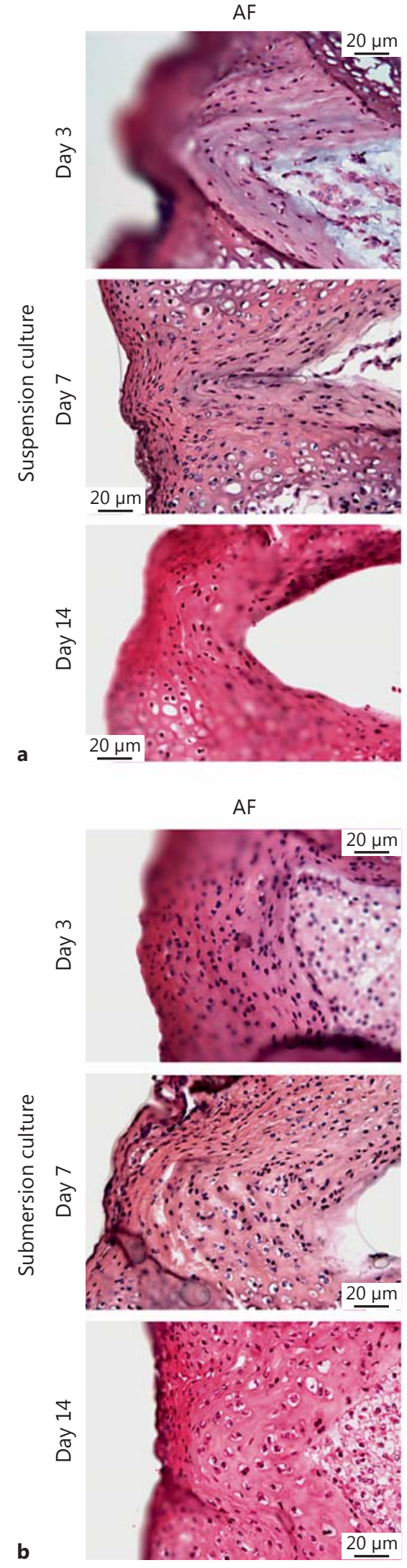

NP
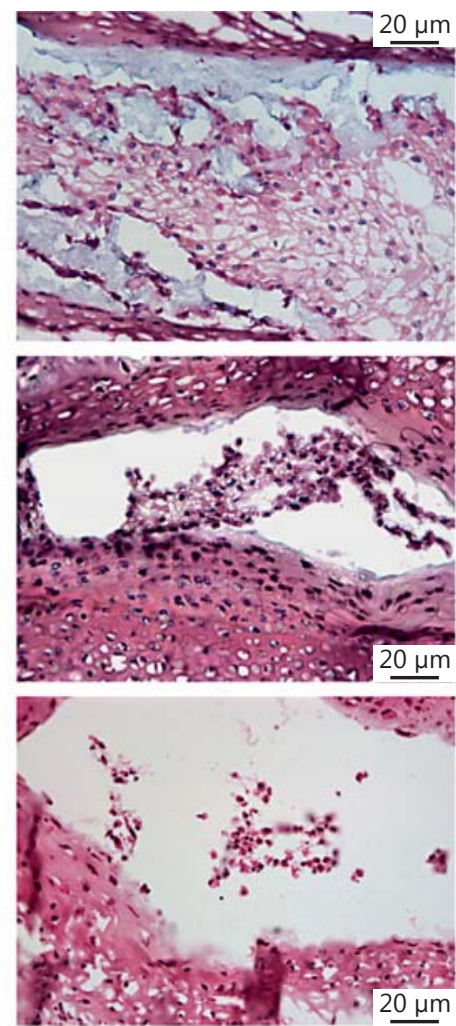

NP
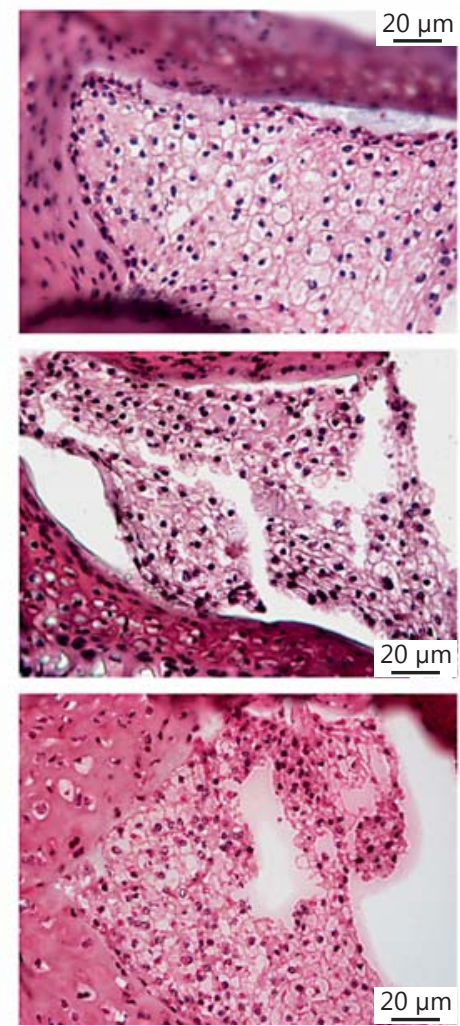

EP
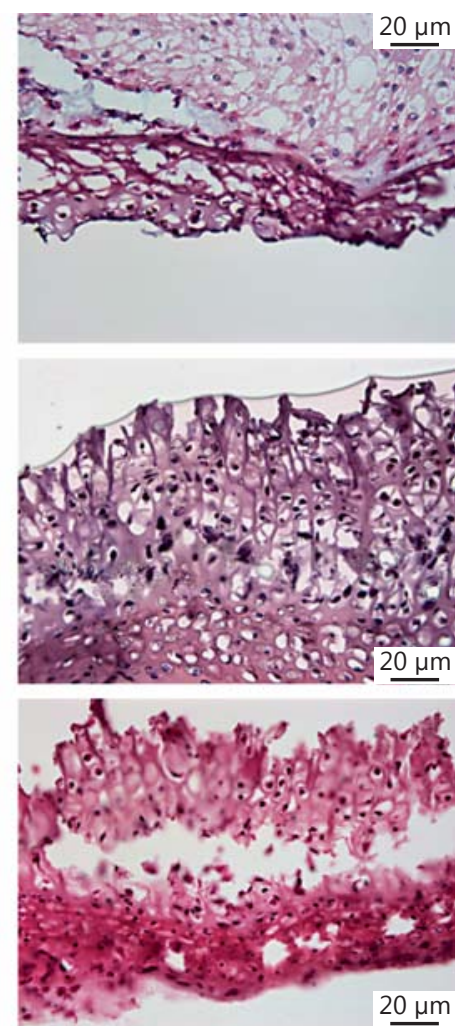

EP
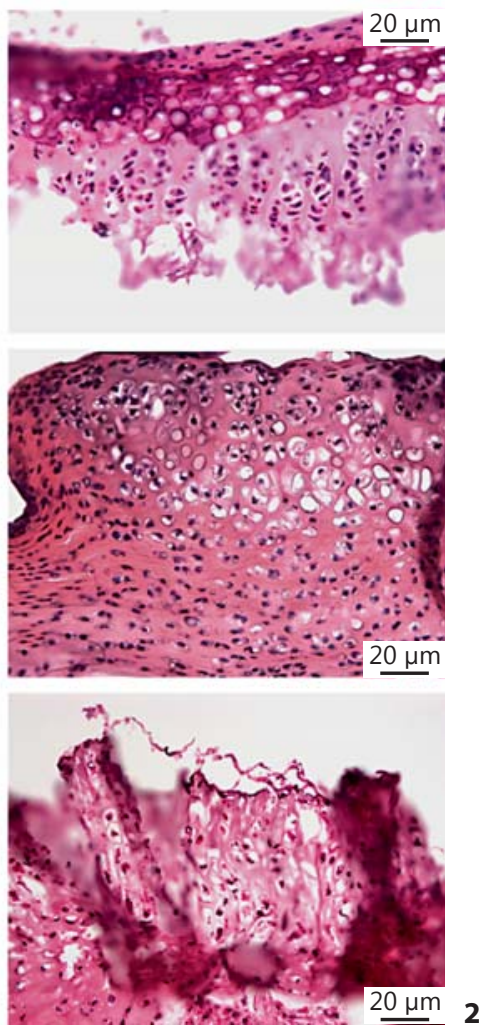
on day 3 (fig. 3a). On day 7, some of the AF and EP cells were relatively healthy, while significant necrosis or apoptosis was observed in the NP cells (fig. 3a). On day 14, apparent necrosis or apoptosis was observed in all three cell types (fig. 3a). These results indicate that the suspension culture system may only support the survival of the IVD tissues up to 7 days in 10\% FBS/DMEM.

In the submersion culture system with $10 \%$ FBS/ DMEM, we found that the AF, NP and EP cells had survived on days 3 and 7 (fig. 3b). Even on day 14, significant portions of AF, NP and EP cells appeared healthy, while there were some cells undergoing necrosis or apoptosis (fig. $3 \mathrm{~b} ; \mathrm{n}=6$ for each time point). These results suggest that under $10 \%$ FBS/DMEM culture conditions, the submersion culture system may provide rather long-term IVD cell survival (e.g. up to 2 weeks), which is better than the suspension culture system.

\section{IVD Tissues in the Submersion Culture System}

Exhibit Higher Cell Proliferation Activity than in the Suspension Culture System

We next examined the cell proliferation activity of the cultured IVD tissues by analyzing the PCNA expression levels. The isolated IVD tissue samples were maintained in $10 \% \mathrm{FBS} / \mathrm{DMEM}$ medium in either submersion culture or suspension culture for 14 days. The IVD samples were collected and subjected to sectioning and immunohistochemical staining with an anti-PCNA antibody. We found that in all three anatomical regions (AF, NP and EP), significantly higher numbers of cells were stained PCNA positive in the submersion culture group than in the suspension culture group (fig. $4 \mathrm{a}$ vs. b). These immunostaining results are consistent with the histological evaluation shown in figures 2 and 3 , and strongly indicate that the submersion culture system may provide the best long-term IVD cell survival under the 10\% FBS/DMEM culture condition.

\section{New Bone Formation and Mineralization in the} Cultured IVD Tissues Can Be Effectively Traced by Dynamic Fluorescent Calcein Labeling

We also tested if new bone formation and/or mineralization in this organ culture system can be assessed using fluorescent calcein labeling, which is commonly used for tracing new bone formation in vivo and in cultured tissue explants [Chen et al., 2010; Zhang et al., 2010; Huang et al., 2012]. When the isolated IVDs were placed in the submersion culture system supplemented with $10 \%$ FBS/ DMEM, ascorbic acid, $\beta$-glycerophosphate and calcein for 7 days, the fluorescence labeling of EP was readily de- tected (fig. 5a). We further tested if dynamic labeling could be achieved when the cultured IVDs were stained with calcein for various labeling times. We found that the EP were distinctly labeled on day 2 (fig. 5b), modestly labeled on day 5 (fig. 5c) and strongly labeled on day 14 (fig. 5d). These results suggest that dynamic fluorescent calcein labeling may be used to trace new bone formation and mineralization in the cultured IVD tissues.

\section{Recombinant Adenovirus Can Mediate Effective Gene Transfer into Cultured IVD Tissues}

It is conceivable that the cultured IVD system can be used to study gene functions in regulating disc cell proliferation and survival, and/or to screen for biological factors that promote IVD fusion. In these cases, an efficient delivery of exogenous genes is highly desirable. Recombinant adenoviruses have been used as one of the most efficient transient gene delivery systems. Here, we tested if recombinant adenovirus vector can effectively transduce the cultured tissues. When the isolated lumbar spine segments, which contain 3-4 IVDs, were cultured in the submersion system and infected with AdGFP, the expression of GFP in the cultured tissue explants was robustly detected after $72 \mathrm{~h}$ of infection (fig. 6a). The GFP signal remained readily detectable at 8 and 14 days after infection, respectively (fig. 6a).

To further focus on the infection of the IVD tissues, we infected the isolated IVD tissues with AdGFP and assessed the GFP expression at various time points. We found that the GFP signal was strongly detectable at $48 \mathrm{~h}$ and lasted at least 14 days (fig. 6b). Further analysis of the transversely sectioned IVD tissues demonstrated that AdGFP mostly infected the EPs and outer layers of the AF region (fig. 6c). The coronal and sagittal sections further supported the above histologic findings, although no significant transduction of the NP cells was observed (data not shown). Nonetheless, the above results strongly indicate that recombinant adenoviruses can be used to efficiently deliver exogenous genes, especially for those genes that express secreted factors, into the cultured IVD system to study gene functions in disc cells.

Fig. 3. The growth and health status of IVD tissues cultured in $10 \%$ FBS serum medium. The isolated lumbar IVD tissue samples were maintained in $10 \%$ FBS medium either in suspension culture (a) or submersion culture $(\mathbf{b} ; \mathrm{n}=6$ per culture condition per time point). On days 3, 7 and 14, the cultured IVD samples were fixed, decalcified and subjected to paraffin embedding and sectioning. Slides were stained with HE. Representative images of the AF, NP and EP regions of the IVD samples are shown.

(For figure see next page.)
Yan et al. 

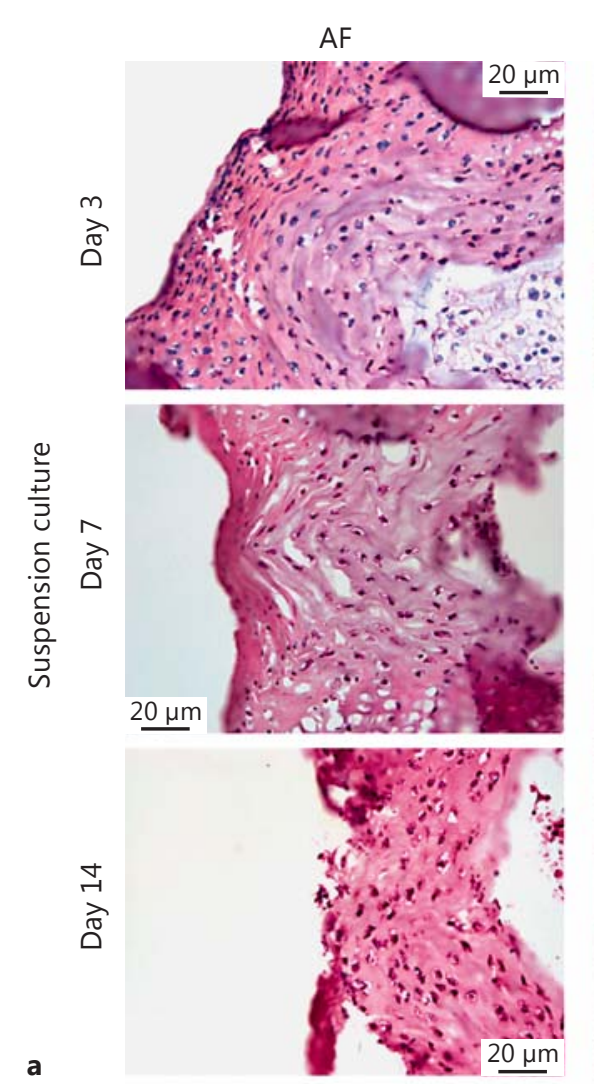

a
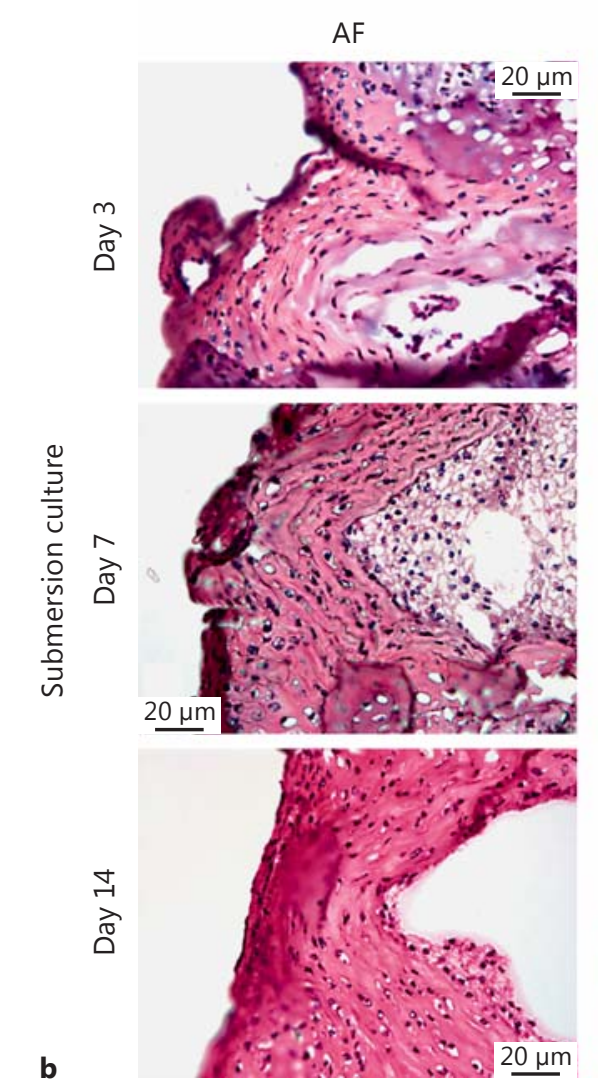
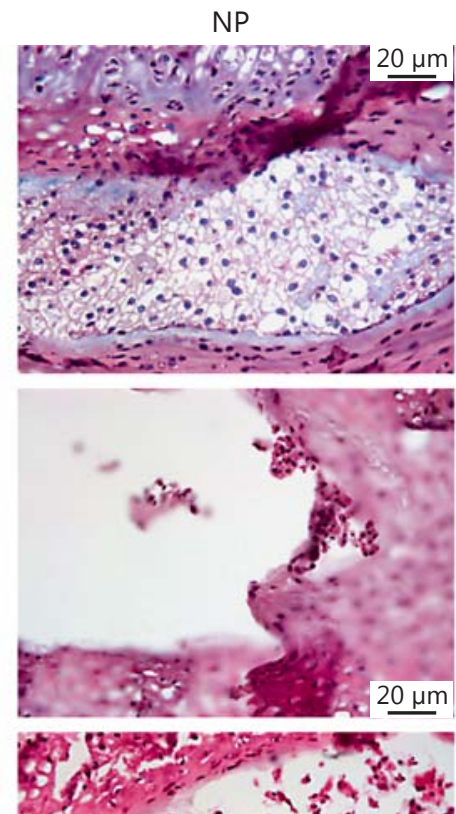

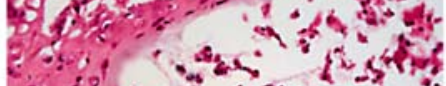

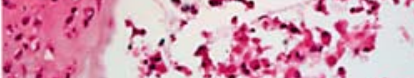

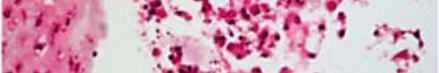

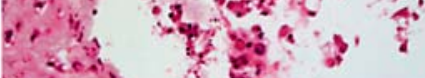

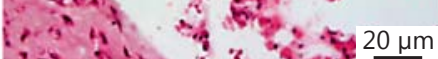
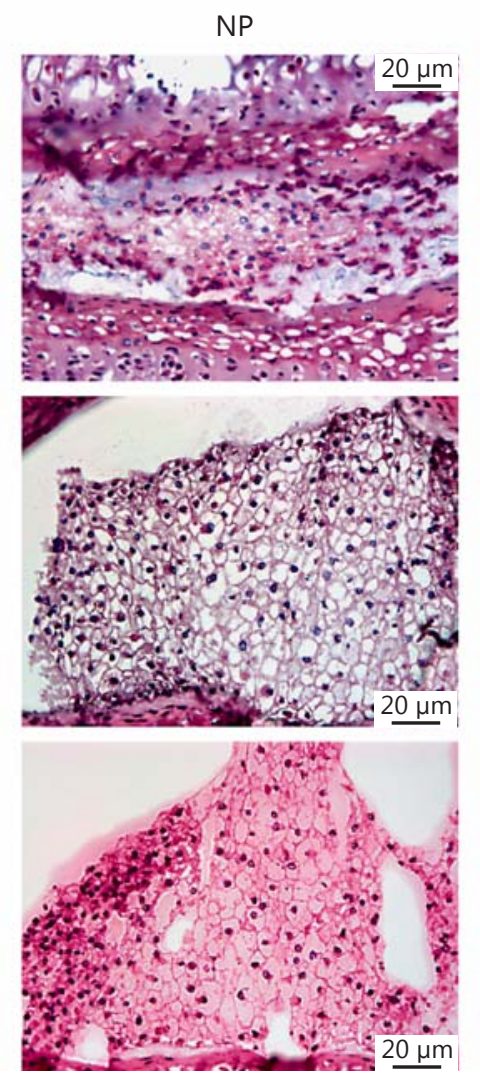
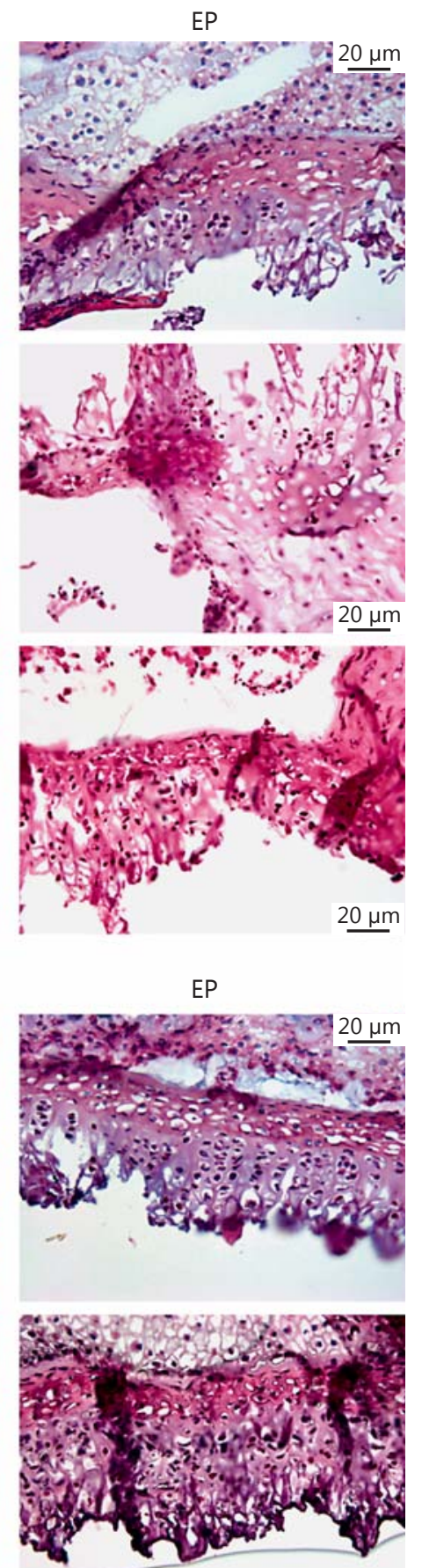

$20 \mu \mathrm{m}$

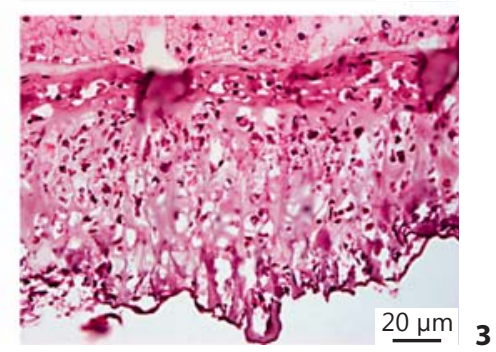


$\mathrm{AF}$

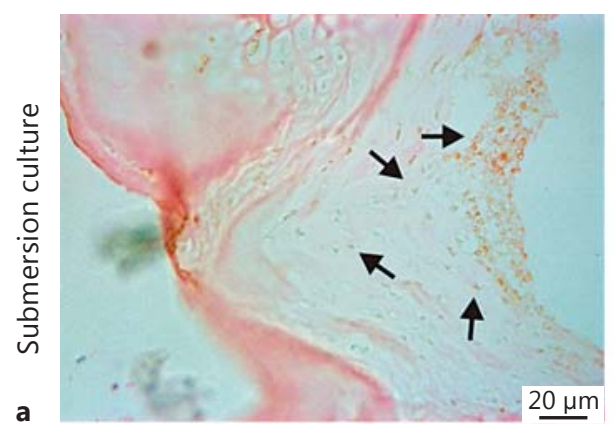

$\mathrm{AF}$

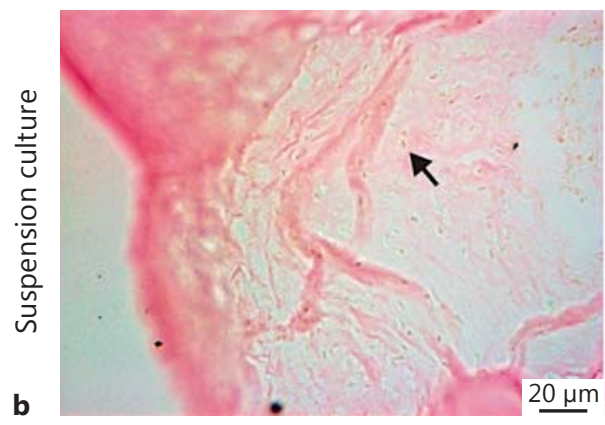

NP

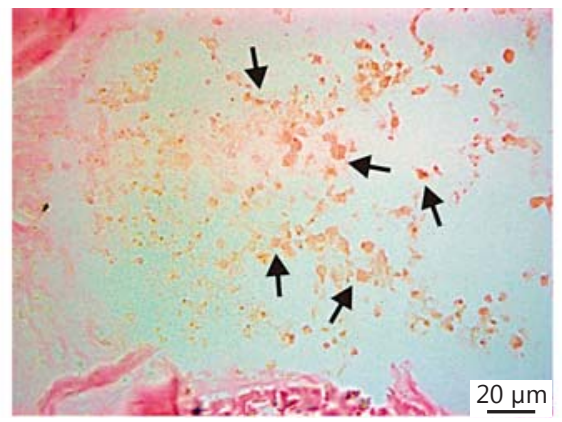

NP

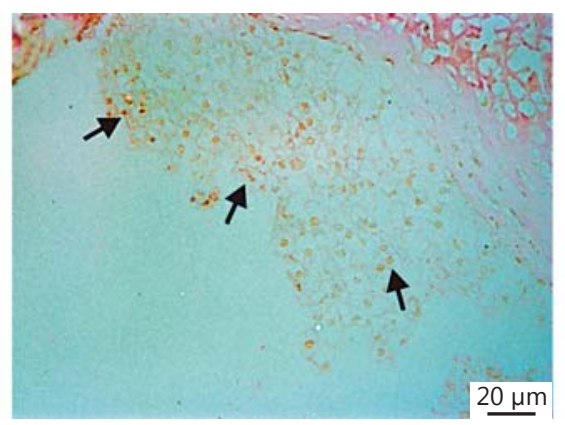

EP

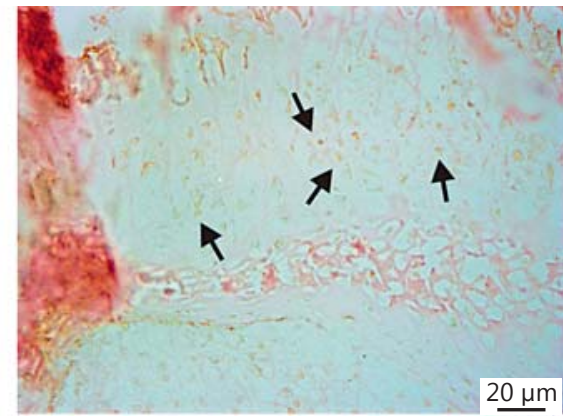

EP

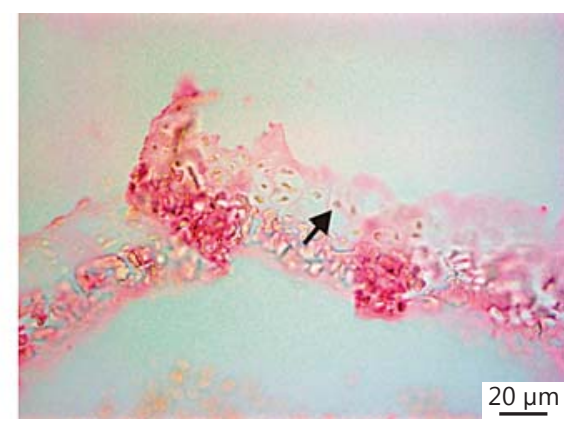

Fig. 4. Cell proliferation activity of cultured IVD samples. The IVD samples maintained in 10\% FBS medium in either submersion culture (a) or suspension culture (b) for 14 days $(\mathrm{n}=5$ each culture condition) were collected and subjected to paraffin embedding and sectioning. The sections were deparaffinized and subjected to immunohistochemical staining with an anti-PCNA antibody
(Santa Cruz Biotechnology). Staining without the primary antibody and with control IgG served as the negative control (data not shown). Representative staining images of the AF, NP and EP regions of the IVD samples are shown. Positively stained cells are indicated with arrows.
The ex vivo IVD Explant Culture System Is a Valuable Tool to Study Disc Cell Biology and Identify Biological Factors That May Prevent Disc Degeneration or

Promote Intervertebral Fusion

The IVD is a complex fibrocartilaginous joint between two vertebral bodies with distinct biochemical properties and unique biomechanical functions. The complex structure and distinct characteristics of IVD tissues pose significant challenges in translating in vitro studies to overall organ functions in vivo. Routine $2 \mathrm{D}$ culture expansion of both AF and NP cells results in downregulation of collagen and proteoglycan production when compared to freshly isolated tissue, although micromass high-density culture techniques can restore some aspects of phenotypic genetic expression [Pelle et al., 2014; Shui et al., 2014]. Thus, there is a critical need to establish robust in vitro and ex vivo IVD organ culture in order to investigate the cellular response and resultant anatomic changes in conditions simulating degeneration in vivo and, hence, the etiology of disc degeneration. Here, we have shown that the minimal IVD unit can be cultured for up to 14 days. Thus, our reported lumbar IVD organ culture system should be a valuable tool for IVD cell biology studies.

We have demonstrated that recombinant adenovirus vectors can effectively transduce the cultured IVD tissues. Recombinant adenoviruses are commonly used to transfer exogenous genes into cells and tissues in vitro and in vivo [He et al., 1998; Breyer et al., 2001; Luo et al., 2005, 2007]. Using an adenoviral vector expressing Sox9, we previously demonstrated that Sox 9 can partially reverse or slow down injury-induced disc degeneration in a rabbit model [Paul et al., 2003]. It is conceivable that the reported IVD culture system can be used to screen for biological factors, especially secreted factors that can support IVD cell survival, inhibit apoptosis, or induce robust bone formation to promote intervertebral fusion for the treatment of lower back pain. These factors may include growth factors, cytokines, morphogens and major signaling molecules [Bray, 2006; 

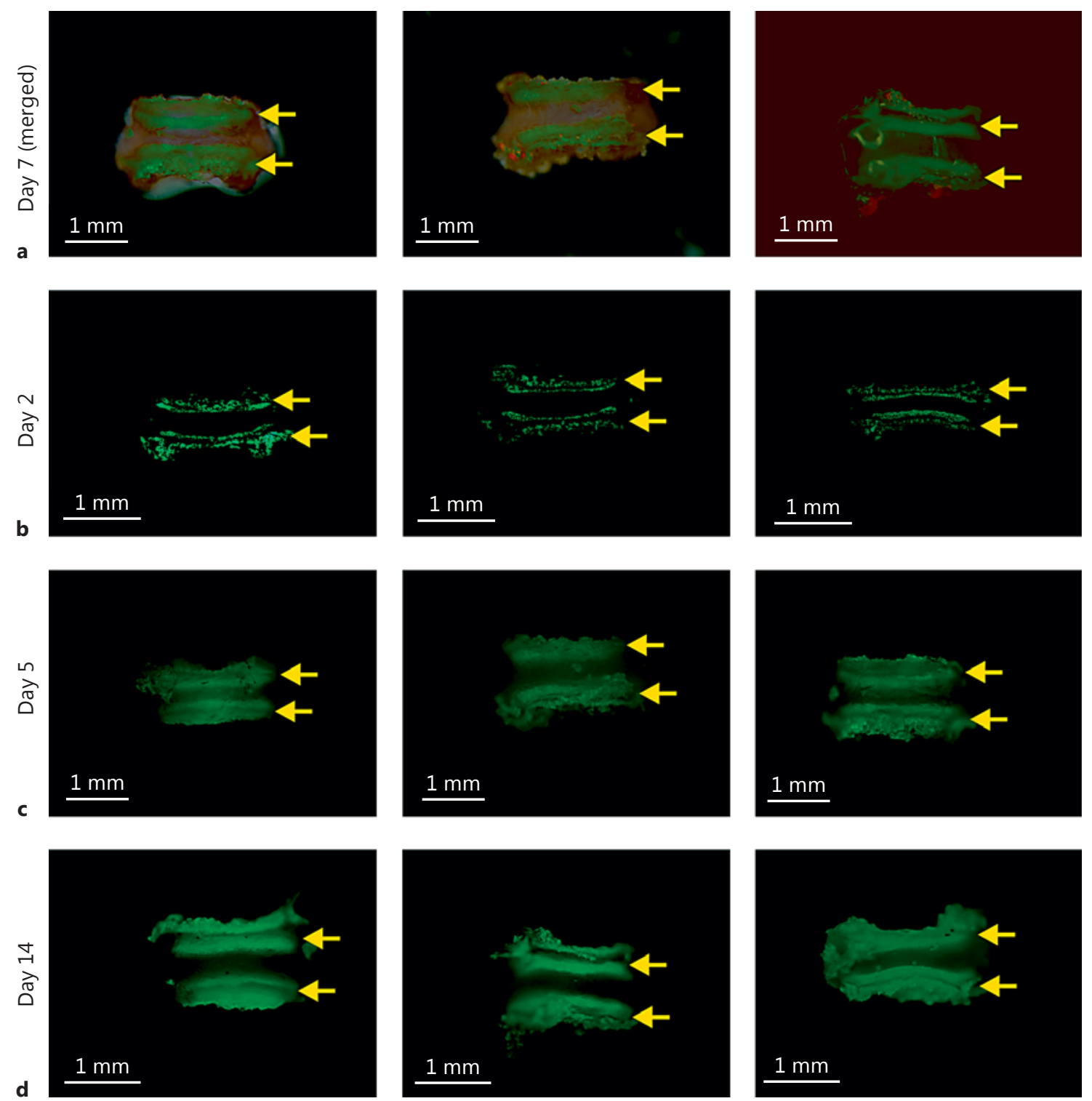

Fig. 5. Efficient and dynamic fluorescent calcein labeling of the cultured IVD tissues. The isolated lumbar IVDs were maintained in $10 \%$ FBS medium containing $100 \mathrm{mM}$ calcein, $50 \mu \mathrm{g} / \mathrm{ml}$ ascorbic acid and $1 \mu \mathrm{M} \beta$-glycerophosphate under submersion culture condition ( $n=5$ per group). On day 7 , the cultured IVDs were examined under a bright-field and fluorescence microscope, and the representative superimposed images are shown (a). For dynamic calcein labeling, the isolated IVD tissues were set up under the same conditions as described in $\mathbf{a}$ ( $\mathrm{n}=5$ per group per time point). The IVD tissues were labeled in calcein-containing medium and harvested for analysis on day 2 (b), day 5 (c) and day 14 (d) under a fluorescence stereomicroscope. The EPs are indicated by arrows. Representative images are shown.
Niederreither and Dolle, 2008; Zanotti and Canalis, 2010; Wagner et al., 2011; Jo et al., 2014; Wang et al., 2014a; Denduluri et al., 2015]. Ultimately, these lines of investigation may lead to the development of innovative therapeutics to prevent, alleviate and/or treat IVD degeneration and resultant lower back pain.

Adenovirus-Mediated Gene Transfer into Mouse IVD Explants
In summary, we established and optimized an in vitro IVD organ culture system using minimal IVD units isolated from the mouse lumbar spine. We showed that these IVD units remain healthy for up to 14 days in submersion culture medium supplemented with $10 \%$ FBS. The new bone formation and mineralization of the EPs in the cul-

Cells Tissues Organs 2015-16;201:38-50 
$72 \mathrm{~h}$

a

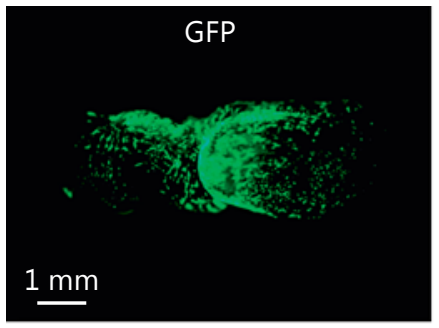

$48 \mathrm{~h}$

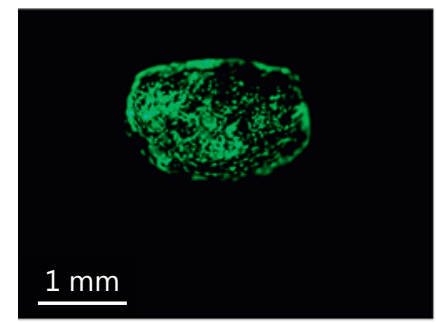

Day 3
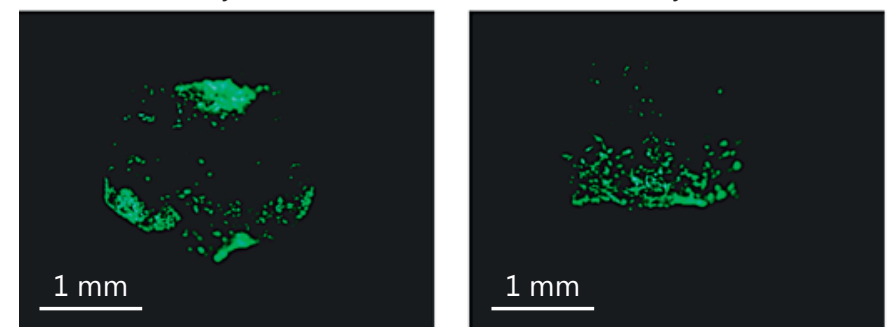

Fig. 6. Adenovirus-mediated effective gene transduction of the cultured IVD tissues. The isolated lumbar spine segments or lumbar IVDs were maintained in 10\% FBS medium and AdGFP $\left(\sim 10^{10}\right.$ pfu) under the submersion culture condition for the indicated time points ( $n=5$ per group per time point). The culture medium was changed every $48 \mathrm{~h}$ until the end points of the assays. a Adenovirus effectively infects cultured lumbar spine segment tissues. The isolated lumbar spine segments were infected with AdGFP for $72 \mathrm{~h}$ and the tissues were examined under fluorescence (GFP) and bright field $(\mathrm{BF})$ to generate the superimposed images. Furthermore, the isolated spine tissues were infected with AdGFP and examined under a fluorescence stereomicroscope on days 8 and 14

tured IVD organ explants can be dynamically assessed by fluorescent calcein labeling. Furthermore, the cultured IVD organ explants can be effectively transduced by recombinant adenovirus, and transgene expression lasts at least 2 weeks. Taken together, our findings demonstrate that the reported IVD organ culture system can be used to study IVD cell biology and/or screen for biological factors that may prevent, alleviate, and/or treat disc degeneration disease.
Day 8

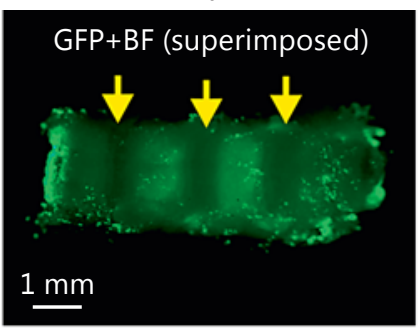

Day 10

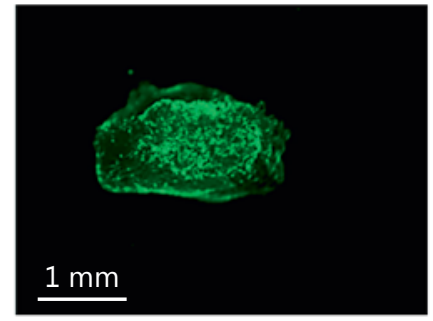

Day 10

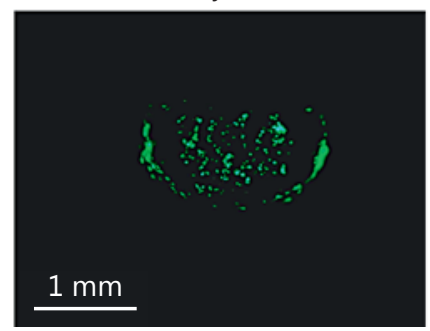

Day 14

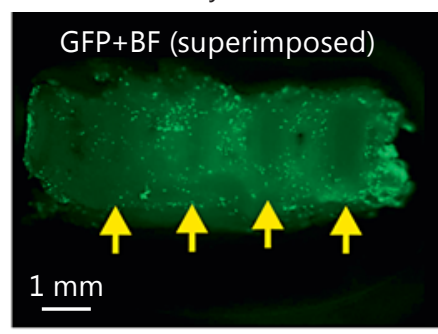

Day 14

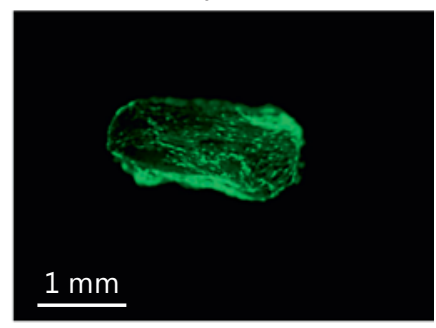

Day 14

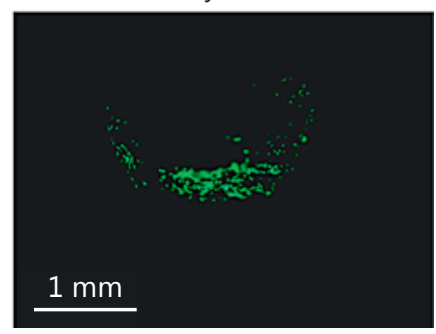

after infection. Representative sample images are shown. Arrows indicate the locations of individual IVDs. $\mathbf{b}$ Adenovirus effectively infects cultured lumbar IVD tissues. The isolated lumbar IVD tissues were infected with AdGFP and GFP expression was assessed under a fluorescence stereomicroscope at the indicated time points. c GFP expression in the sectioned tissues of the adenovirusinfected lumbar IVD tissues. The isolated lumbar IVD tissues were infected with AdGFP and harvested at the indicated time points. GFP expression in the transverse frozen sections was examined under a fluorescence stereomicroscope at the indicated time points. Representative images are shown.

\section{Acknowledgments}

The authors thank Dr. Linda Degenstein of The University of Chicago Transgenics/ES Cell Technology Mouse Core Facility for providing the animals used in the study. The reported work was supported in part by research grants from the National Institutes of Health (AT004418 to T.C.H.), the North American Spine Society (T.C.H.), the Scoliosis Research Society (M.J.L.), the 973 Program of Ministry of Science and Technology (MOST) of China (No. 2011CB707900 to T.C.H. and Z.L.D.), and the Natural Science Foundation of China (Grant No. 81272005 to Z.L.D.). This work was also supported in part by The University of Chicago Core 
Facility Subsidy grant from the National Center for Advancing Translational Sciences (NCATS) of the National Institutes of Health through Grant UL1 TR000430. Funding sources were not involved in the study design, in the collection, analysis and interpretation of data, in the writing of the report or in the decision to submit the paper for publication.

\section{Disclosure Statement}

The authors declare no conflicts of interest.

\section{References}

Andersson, G.B. (1999) Epidemiological features of chronic low-back pain. Lancet 354: 581585.

Bray, S.J. (2006) Notch signalling: a simple pathway becomes complex. Nat Rev Mol Cell Biol 7: 678-689.

Breyer, B., W. Jiang, H. Cheng, L. Zhou, R. Paul, T. Feng, T.C. He (2001) Adenoviral vectormediated gene transfer for human gene therapy. Curr Gene Ther 1: 149-162.

Chan, W.C., K.L. Sze, D. Samartzis, V.Y. Leung, D. Chan (2011) Structure and biology of the intervertebral disk in health and disease. Orthop Clin North Am 42: 447-464.

Chen, L., W. Jiang, J. Huang, B.C. He, G.W. Zuo, W. Zhang, Q. Luo, Q. Shi, B.Q. Zhang, E.R. Wagner, J. Luo, M. Tang, C. Wietholt, X. Luo, Y. Bi, Y. Su, B. Liu, S.H. Kim, C.J. He, Y. Hu, J. Shen, F. Rastegar, E. Huang, Y. Gao, J.L. Gao, J.Z. Zhou, R.R. Reid, H.H. Luu, R.C. Haydon, T.C. He, Z.L. Deng (2010) Insulinlike growth factor 2 (IGF-2) potentiates BMP9 -induced osteogenic differentiation and bone formation. J Bone Miner Res 25: 2447 2459.

Chen, X., J. Cui, Z. Yan, H. Zhang, X. Chen, N. Wang, P. Shah, F. Deng, C. Zhao, N. Geng, M. Li, S.K. Denduluri, R.C. Haydon, H.H. Luu, R.R. Reid, T.C. He (2015) Sustained high level transgene expression in mammalian cells mediated by the optimized piggyBac transposon system. Genes Dis 2: 96-105.

Cheng, H., W. Jiang, F.M. Phillips, R.C. Haydon, Y. Peng, L. Zhou, H.H. Luu, N. An, B. Breyer, P. Vanichakarn, J.P. Szatkowski, J.Y. Park, T.C. He (2003) Osteogenic activity of the fourteen types of human bone morphogenetic proteins (BMPs). J Bone Joint Surg Am 85A: $1544-1552$.

Dahia, C.L., E.J. Mahoney, A.A. Durrani, C. Wylie (2011) Intercellular signaling pathways active during and after growth and differentiation of lumbar vertebral growth plate. Spine 36: 1071-1080.

Denduluri, S.K., O. Idowu, Z. Wang, Z. Liao, Z. Yan, M.K. Mohammed, J. Ye, Q. Wei, J. Wang, L. Zhao, H.H. Luu (2015) Insulin-like growth factor (IGF) signaling in tumorigenesis and the development of cancer drug resistance. Genes Dis 2: 13-25.

Deng, F., X. Chen, Z. Liao, Z. Yan, Z. Wang, Y. Deng, Q. Zhang, Z. Zhang, J. Ye, M. Qiao, R. Li, S. Denduluri, J. Wang, Q. Wei, M. Li, N. Geng, L. Zhao, G. Zhou, P. Zhang, H.H. Luu, R.C. Haydon, R.R. Reid, T. Yang, T.C. He
(2014) A simplified and versatile system for the simultaneous expression of multiple siRNAs in mammalian cells using Gibson DNA Assembly. PLoS One 9: e113064.

Eskola, P.J., S. Lemmela, P. Kjaer, S. Solovieva, M. Mannikko, N. Tommerup, A. Lind-Thomsen, K. Husgafvel-Pursiainen, K.M. Cheung, D. Chan, D. Samartzis, J. Karppinen (2012) Genetic association studies in lumbar disc degeneration: a systematic review. PLoS One 7: e49995.

Gantenbein, B., S. Illien-Junger, S.C. Chan, J. Walser, L. Haglund, S.J. Ferguson, J.C. Iatridis, S. Grad (2015) Organ culture bioreactors - platforms to study human intervertebral disc degeneration and regenerative therapy. Curr Stem Cell Res Ther 10: 339-352.

Gao, Y., E. Huang, H. Zhang, J. Wang, N. Wu, X. Chen, N. Wang, S. Wen, G. Nan, F. Deng, Z. Liao, D. Wu, B. Zhang, J. Zhang, R.C. Haydon, H.H. Luu, L.L. Shi, T.C. He (2013) Crosstalk between $\mathrm{Wnt} / \beta$-catenin and estrogen receptor signaling synergistically promotes osteogenic differentiation of mesenchymal progenitor cells. PLoS One 8: e82436.

Gorth, D.J., K.E. Lothstein, J.A. Chiaro, M.J. Farrell, G.R. Dodge, D.M. Elliott, N.R. Malhotra, R.L. Mauck, L.J. Smith (2015) Hypoxic regulation of functional extracellular matrix elaboration by nucleus pulposus cells in longterm agarose culture. J Orthop Res 33: 747754.

He, T.C., S. Zhou, L.T. da Costa, J. Yu, K.W. Kinzler, B. Vogelstein (1998) A simplified system for generating recombinant adenoviruses. Proc Natl Acad Sci USA 95: 25092514.

Huang, E., G. Zhu, W. Jiang, K. Yang, Y. Gao, Q. Luo, J.L. Gao, S.H. Kim, X. Liu, M. Li, Q. Shi, N. Hu, L. Wang, H. Liu, J. Cui, W. Zhang, R. Li, X. Chen, Y.H. Kong, J. Zhang, J. Wang, J. Shen, Y. Bi, J. Statz, B.C. He, J. Luo, H. Wang, F. Xiong, H.H. Luu, R.C. Haydon, L. Yang, T.C. He (2012) Growth hormone synergizes with BMP9 in osteogenic differentiation by activating the JAK/STAT/IGF1 pathway in murine multilineage cells. J Bone Miner Res 27: 1566-1575.

Jo, A., S.K. Denduluri, B. Zhang, Z. Wang, L. Yin, Z. Yan, R. Kang, L.L. Shi, J. Mok, M.J. Lee, R.C. Haydon (2014) The versatile functions of Sox9 in development, stem cells, and human diseases. Genes Dis 1: 149-161.

Kang, Q., W.X. Song, Q. Luo, N. Tang, J. Luo, X. Luo, J. Chen, Y. Bi, B.C. He, J.K. Park, W.
Jiang, Y. Tang, J. Huang, Y. Su, G.H. Zhu, Y. He, H. Yin, Z. Hu, Y. Wang, L. Chen, G.W. Zuo, X. Pan, J. Shen, T. Vokes, R.R. Reid, R.C. Haydon, H.H. Luu, T.C. He (2009) A comprehensive analysis of the dual roles of BMPs in regulating adipogenic and osteogenic differentiation of mesenchymal progenitor cells. Stem Cells Dev 18: 545-559.

Kang, Q., M.H. Sun, H. Cheng, Y. Peng, A.G. Montag, A.T. Deyrup, W. Jiang, H.H. Luu, J. Luo, J.P. Szatkowski, P. Vanichakarn, J.Y. Park, Y. Li, R.C. Haydon, T.C. He (2004) Characterization of the distinct orthotopic bone-forming activity of 14 BMPs using recombinant adenovirus-mediated gene delivery. Gene Ther 11: 1312-1320.

Kepler, C.K., R.K. Ponnappan, C.A. Tannoury, M.V. Risbud, D.G. Anderson (2013) The molecular basis of intervertebral disc degeneration. Spine J 13: 318-330.

Kong, Y., H. Zhang, X. Chen, W. Zhang, C. Zhao, N. Wang, N. Wu, Y. He, G. Nan, H. Zhang, S. Wen, F. Deng, Z. Liao, D. Wu, J. Zhang, X. Qin, R.C. Haydon, H.H. Luu, T.C. He, L. Zhou (2013) Destabilization of heterologous proteins mediated by the GSK3 $\beta$ phosphorylation domain of the $\beta$-catenin protein. Cell Physiol Biochem 32: 1187-1199.

Liu, X., J. Qin, Q. Luo, Y. Bi, G. Zhu, W. Jiang, S.H. Kim, M. Li, Y. Su, G. Nan, J. Cui, W. Zhang, R. Li, X. Chen, Y. Kong, J. Zhang, J. Wang, M.R. Rogers, H. Zhang, W. Shui, C. Zhao, N. Wang, X. Liang, N. Wu, Y. He, H.H. Luu, R.C. Haydon, L.L. Shi, T. Li, T.C. He, M. Li (2013) Cross-talk between EGF and BMP9 signalling pathways regulates the osteogenic differentiation of mesenchymal stem cells. J Cell Mol Med 17: 1160-1172.

Luo, J., Z.L. Deng, X. Luo, N. Tang, W.X. Song, J. Chen, K.A. Sharff, H.H. Luu, R.C. Haydon, K.W. Kinzler, B. Vogelstein, T.C. He (2007) A protocol for rapid generation of recombinant adenoviruses using the AdEasy system. Nat Protoc 2: 1236-1247.

Luo, J., M.H. Sun, Q. Kang, Y. Peng, W. Jiang, H.H. Luu, Q. Luo, J.Y. Park, Y. Li, R.C. Haydon, T.C. He (2005) Gene therapy for bone regeneration. Curr Gene Ther 5: 167-179.

Niederreither, K., P. Dolle (2008) Retinoic acid in development: towards an integrated view. Nat Rev Genet 9: 541-553.

Pattappa, G., Z. Li, M. Peroglio, N. Wismer, M. Alini, S. Grad (2012) Diversity of intervertebral disc cells: phenotype and function. J Anat 221: 480-496. 
- Paul, R., R.C. Haydon, H. Cheng, A. Ishikawa, N. Nenadovich, W. Jiang, L. Zhou, B. Breyer, T. Feng, P. Gupta, T.C. He, F.M. Phillips (2003) Potential use of sox 9 gene therapy for intervertebral degenerative disc disease. Spine 28: 755-763.

Pelle, D.W., J.D. Peacock, C.L. Schmidt, K. Kampfschulte, D.J. Scholten 2nd, S.S. Russo, K.J. Easton, M.R. Steensma (2014) Genetic and functional studies of the intervertebral disc: a novel murine intervertebral disc model. PLoS One 9: e112454.

Raj, P.P. (2008) Intervertebral disc: anatomy physiology - pathophysiology - treatment. Pain Pract 8: 18-44.

Roughley, P.J. (2004) Biology of intervertebral disc aging and degeneration: involvement of the extracellular matrix. Spine 29: 2691-2699.

-Shui, W., L. Yin, J. Luo, R. Li, W. Zhang, J. Zhang, W. Huang, N. Hu, X. Liang, Z.L. Deng, Z. Hu, L.L. Shi, H.H. Luu, R.C. Haydon, T.C. He, S.H. Ho (2014) Characterization of chondrocyte scaffold carriers for cell-based gene therapy in articular cartilage repair. J Biomed Mater Res 101: 3542-3550.

-Sivakamasundari, V., T. Lufkin (2012) Bridging the gap: understanding embryonic intervertebral disc development. Cell Dev Biol 1: 103107.

Wagner, E.R., G. Zhu, B.Q. Zhang, Q. Luo, Q. Shi, E. Huang, Y. Gao, J.L. Gao, S.H. Kim, F. Rastegar, K. Yang, B.C. He, L. Chen, G.W. Zuo, Y. Bi, Y. Su, J. Luo, X. Luo, J. Huang, Z.L. Deng, R.R. Reid, H.H. Luu, R.C. Haydon, T.C. He (2011) The therapeutic potential of the Wnt signaling pathway in bone disorders. Curr Mol Pharmacol 4: 14-25.

-Wang, J., H. Zhang, W. Zhang, E. Huang, N. Wang, N. Wu, S. Wen, X. Chen, Z. Liao, F. Deng, L. Yin, J. Zhang, Q. Zhang, Z. Yan, W. Liu, Z. Zhang, J. Ye, Y. Deng, H.H. Luu, R.C. Haydon, T.C. He, F. Deng (2014a) Bone morphogenetic protein-9 (BMP9) effectively in- duces osteo/odontoblastic differentiation of the reversibly immortalized stem cells of dental apical papilla. Stem Cells Dev 23: 14051416.

Wang, N., H. Zhang, B.Q. Zhang, W. Liu, Z. Zhang, M. Qiao, H. Zhang, F. Deng, N. Wu, X. Chen, S. Wen, J. Zhang, Z. Liao, Q. Zhang, Z. Yan, L. Yin, J. Ye, Y. Deng, H.H. Luu, R.C. Haydon, H. Liang, T.C. He (2014b) Adenovirus-mediated efficient gene transfer into cultured three-dimensional organoids. PLoS One 9: e93608.

Wang, N., W. Zhang, J. Cui, H. Zhang, X. Chen, R. Li, N. Wu, X. Chen, S. Wen, J. Zhang, L. Yin, F. Deng, Z. Liao, Z. Zhang, Q. Zhang, Z. Yan, W. Liu, J. Ye, Y. Deng, Z. Wang, M. Qiao, H.H. Luu, R.C. Haydon, L.L. Shi, H. Liang, T.C. He (2014c) The piggyBac transposonmediated expression of SV40 T antigen efficiently immortalizes mouse embryonic fibroblasts (MEFs). PLoS One 9: e97316.

Wang, Y., S. Hong, M. Li, J. Zhang, Y. Bi, Y. He, X. Liu, G. Nan, Y. Su, G. Zhu, R. Li, W. Zhang, J. Wang, H. Zhang, Y. Kong, W. Shui, N. Wu, Y. He, X. Chen, H.H. Luu, R.C. Haydon, L.L. Shi, T.C. He, J. Qin (2013) Noggin resistance contributes to the potent osteogenic capability of BMP9 in mesenchymal stem cells. J Orthop Res 31: 1796-1803.

Wen, S., H. Zhang, Y. Li, N. Wang, W. Zhang, K. Yang, N. Wu, X. Chen, F. Deng, Z. Liao, J. Zhang, Q. Zhang, Z. Yan, W. Liu, Z. Zhang, J. Ye, Y. Deng, G. Zhou, H.H. Luu, R.C. Haydon, L.L. Shi, T.C. He, G. Wei (2014) Characterization of constitutive promoters for piggyBac transposon-mediated stable transgene expression in mesenchymal stem cells (MSCs). PLoS One 9: e94397.

Wu, N., H. Zhang, F. Deng, R. Li, W. Zhang, X. Chen, S. Wen, N. Wang, J. Zhang, L. Yin, Z. Liao, Z. Zhang, Q. Zhang, Z. Yan, W. Liu, D. Wu, J. Ye, Y. Deng, K. Yang, H.H. Luu, R.C. Haydon, T.C. He (2014) Overexpression of
Ad5 precursor terminal protein accelerates recombinant adenovirus packaging and amplification in HEK-293 packaging cells. Gene Ther 21: 629-637.

Zanotti, S., E. Canalis (2010) Notch and the skeleton. Mol Cell Biol 30: 886-896.

Zhang, H., J. Wang, F. Deng, E. Huang, Z. Yan, Z. Wang, Y. Deng, Q. Zhang, Z. Zhang, J. Ye, M. Qiao, R. Li, J. Wang, Q. Wei, G. Zhou, H.H. Luu, R.C. Haydon, T.C. He, F. Deng (2015) Canonical Wnt signaling acts synergistically on BMP9-induced osteo/odontoblastic differentiation of stem cells of dental apical papilla (SCAPs). Biomaterials 39: 145-154.

Zhang, J., Y. Weng, X. Liu, J. Wang, W. Zhang, S.H. Kim, H. Zhang, R. Li, Y. Kong, X. Chen, W. Shui, N. Wang, C. Zhao, N. Wu, Y. He, G. Nan, X. Chen, S. Wen, H. Zhang, F. Deng, L. Wan, H.H. Luu, R.C. Haydon, L.L. Shi, T.C. He, Q. Shi (2013) Endoplasmic reticulum (ER) stress inducible factor cysteine-rich with EGF-like domains 2 (Creld2) is an important mediator of BMP9-regulated osteogenic differentiation of mesenchymal stem cells. PLoS One 8: e73086.

Zhang, W., Z.L. Deng, L. Chen, G.W. Zuo, Q. Luo, Q. Shi, B.Q. Zhang, E.R. Wagner, F. Rastegar, S.H. Kim, W. Jiang, J. Shen, E. Huang, Y. Gao, J.L. Gao, J.Z. Zhou, J. Luo, J. Huang, X. Luo, Y. Bi, Y. Su, K. Yang, H. Liu, H.H. Luu, R.C. Haydon, T.C. He, B.C. He (2010) Retinoic acids potentiate BMP9-induced osteogenic differentiation of mesenchymal progenitor cells. PLoS One 5: e11917.

Zhao, C., N. Wu, F. Deng, H. Zhang, N. Wang, W. Zhang, X. Chen, S. Wen, J. Zhang, L. Yin, Z. Liao, Z. Zhang, Q. Zhang, Z. Yan, W. Liu, D. Wu, J. Ye, Y. Deng, G. Zhou, H.H. Luu, R.C. Haydon, W. Si, T.C. He (2014) Adenovirus-mediated gene transfer in mesenchymal stem cells can be significantly enhanced by the cationic polymer polybrene. PLoS One 9: e92908. 